\title{
AVALIAÇÃO DO SISTEMA DE ALOJAMENTO CONJUNTO NA MATERNIDADE D. FRANCISCA CINTRA SILVA DA SANTA CASA DE SÃO CARLOS-SP
}

\author{
Maria Isabel Ruiz Beretta* \\ Dalcilene Aparecida Frasson** \\ Lúcia Helena Rubira Pacífico** \\ Fátima Elizabeth Denari***
}

BERETTA, M.I.R.; FRASSON, D.A.; PACÍFICO, L.H.R.; DENARI, F.E. Avaliação do sistema de alojamento conjunto na maternidade D. Francisca Cintra Silva da Santa Casa de São Carlos-SP. Rev.latino-am.enfermagem, Ribeirão Preto, v. 8, n. 3, p. 59-66, julho 2000.

O alojamento conjunto foi implantado em uma maternidade do município de São Carlos-São Paulo em 1997. Este estudo analisa a aceitação do sistema pelas mães e como a Enfermagem participa deste trabalho. Os resultados mostraram que as mães estão satisfeitas. Entretanto, a Enfermagem não concorda, sugerindo a necessidade de se aumentar e qualificar o quadro de funcionários.

UNITERMOS: alojamento conjunto, enfermagem materno-infantil

\section{INTRODUÇÃO}

O relacionamento mãe-filho vêm sendo um dos assuntos de maior destaque nos últimos anos e tem despertado a atenção dos profissionais da área da Saúde. Enfatiza-se a assistência integral ao Recém-Nascido (RN), com vistas a resguardar suas necessidades afetivas, equilíbrio emocional e processo de socialização, situação tal que poderia ser concretizada através da prática do Alojamento Conjunto.

Gesell \& Ilg apud CZAR \& RIBEIRO (1981) disseram que a expressão Alojamento Conjunto (AC) traduzido do inglês "Rooming-in" foi primeiramente empregada no seu livro "Infant and child in the culture of today".

De acordo com FONTES (1984) o Alojamento Conjunto é um sistema em que o RN permanece ao lado da mãe desde o momento do parto até a alta da maternidade sendo um local de ensino e aprendizagem, em que a permanência do $\mathrm{RN}$ ao lado do leito materno permite que sejam dadas orientações e que essas sejam checadas, quando a mãe executa a tarefa de cuidar de seu filho.

Segundo BASSETTO et al. (1998), o Alojamento Conjunto define-se por um sistema hospitalar em que o $\mathrm{RN}$, estando livre de patologias, poderá permanecer ao lado da mãe, em um mesmo ambiente, por ocasião da hospitalização pós parto, possibilitando a prestação de todos os cuidados assistenciais e orientação à mãe sobre a saúde do binômio mãe-filho. O RN deve ter boa vitalidade e boa sucção e com controle térmico adequado, ou seja, os que pesarem $2.000 \mathrm{~g}$ ou mais, produtos de gestação de 35 semanas e Apgar maior que 5 no primeiro minuto de vida. Após o nascimento, o recém-nascido receberá os cuidados de rotina na sala de admissão do berçário, onde será realizado o primeiro exame clínico. $\mathrm{Na}$ ausência de anormalidades, ele será transferido para o Alojamento Conjunto depois das primeiras quatro horas de vida. Os nascidos com icterícia fisiológica passível de tratamento por fototerapia ou com malformações congênitas mínimas que não impeçam a sucção da mama são indicados para fazer parte deste sistema. Participam deste sistema todas as puérperas sadias, sobretudo as preparadas no pré-natal ou motivadas por experiências anteriores. Não há relação com o tipo de parto. Não participam do Alojamento Conjunto, a critério do Obstetra, as puérperas com patologias que impeçam ou coloquem em risco a presença do $\mathrm{RN}$ a seu lado no hospital, como: doença mental grave ou doenças infecto contagiosas. Também são excluídas as mães cujos RNs permanecem no berçário sob observação ou tratamento médico.

\footnotetext{
* Professor Assistente do Departamento de Enfermagem da UFSCar

** Enfermeira Graduada na UFSCar

*** Professor Doutor do Departamento de Psicologia da UFSCar
} 
Para BRENELLI (1995), é no Alojamento Conjunto que se favorece a aceitação da maternidade, aumentando-se os laços da relação mãe-filho por permitir o contato precoce e íntimo entre o binômio, os quais são mais satisfeitos emocionalmente por sentirem maior proteção. Este contato precoce facilita a prática da amamentação, pois estando no Alojamento Conjunto, a mãe amamentará mais e por mais tempo, o que facilitará a apojadura, permitindo que se estabeleça a lactação e trazendo à criança outros benefícios, como aumento da absorção de nutrientes e ganho de peso acelerado durante os primeiros dias de vida. CIAMPO (1994) cita o fato de que o tempo de desmame para crianças que utilizaram o sistema de Alojamento Conjunto foi de 10 meses e para as que ficaram no berçário convencional foi de 8 meses.

SILVA et al. (1995) salientam que o Alojamento Conjunto é fundamental para o incentivo do início da amamentação, encontrando-se pelo menos $50 \%$ de crianças que saem de hospitais com este sistema sendo amamentados.

FREDDI \& SCHUBERT (1987) ao realizarem um estudo com puérperas, observaram que o sistema de permanência contínua em que a criança fica o tempo todo ao lado da mãe é o escolhido pelas primíparas que querem a maior permanência do filho para que possam aprender a cuidar dele sob orientação da enfermeira; entretanto muitas mulheres, principalmente as multíparas, escolhem o sistema de permanência intermitente que lhes favorece descansar melhor durante a noite.

CARVALHO \& THOMSON (1987) verificaram através de seu estudo que a maioria $(71,3 \%)$ das puérperas tiveram preferência pelo Alojamento Conjunto, embora apenas $19,6 \%$ delas tivesse experiência com esse sistema e, também que o início da amamentação materna foi mais precoce.

PRATA (1997) observou em seu estudo que as ações educativas de enfermagem do sistema Alojamento Conjunto, quanto à higiene do recém-nascido, atendem as necessidades da puérpera no domicílio. Foram entrevistadas 50 puérperas com o mínimo de quatro dias no domicílio após alta da maternidade e, a maioria da amostra considerou necessárias as orientações oferecidas neste sistema.

Pode-se considerar que o sistema de Alojamento Conjunto é utilizado numa tentativa de corrigir as desvantagens inerentes ao berçário convencional e que dizem respeito principalmente ao relacionamento mãefilho-pais-parentes que foi completamente alterado pela localização do RN no berçário tradicional.

Historicamente, a literatura vêm apontando para a prática do Alojamento Conjunto desde 1880. Klaus \& Kennell apud CZAR \& RIBEIRO (1981) disseram que até o ano de 1880, os hospitais eram construídos sem berçário e o RN era colocado ao lado da mãe, que cuidava dele e o alimentava.

Em 1896 ocorreu a primeira mudança na assistência ao RN e à mãe, quando Martin Cooney utilizou a incubadora para atendimento ao prematuro. Com isso, em quatro décadas, conseguiu a recuperação de 5.000 (cinco mil) RN, porém não permitia a participação das mães nos cuidados prestados. A isto foi atribuída a dificuldade de aceitação pelos pais, do filho pré-termo.

No ano 1900 houve o isolamento mais restrito de todos os RNs, devido a alta mortalidade infantil ocorrida naquela época, tendo como causa a diarréia epidêmica, infecção respiratória e equipamentos inadequados.

De acordo com a literatura, entre os anos de 1945 - 1960, continuou-se a recomendação do isolamento e a mínima manipulação do $\mathrm{RN}$, sendo proibido qualquer visita ao berçário, até mesma a da mãe.

No Brasil, as primeiras instalações de berçário surgiram em 1945 e, seguindo a tendência internacional, implantaram-se unidades de Alojamento Conjunto face às normas e recomendações das Organizações Governamentais, Científicas e Institucionais. As instalações dessas unidades tornaram-se obrigatórias em todos os hospitais e demais estabelecimentos que realizavam atenção ao parto (BRASIL, 1991; CAMPOS et al., 1994).

De acordo com a UNICEF (1993), este sistema deve obedecer as seguintes normas:

- O Alojamento Conjunto deve ser iniciado na sala de parto.

- A amamentação do $\mathrm{RN}$ deve ser praticada em regime de livre demanda, isto é, sem horários fixos.

- É contra-indicado o uso de bicos (chupetas, mamadeiras e chucas).

- É contra-indicado o uso de água, solução glicosada, chá, fórmulas lácteas ou outros alimentos, exceto em casos clinicamente indicados como RNs internados nas Unidades Neonatais ou em casos de mães portadoras do vírus HIV.

- A Púerpera deve ser continuamente apoiada e informada, durante sua internação, sobre aspectos relacionados ao aleitamento materno.

- O aleitamento cruzado está contra indicado.

- É proibida a distribuição de bicos, mamadeiras, propagandas e amostras de substitutos do leite materno. - Os horários de visita para os pais devem ser flexíveis e com a maior duração possível.

- Destinar local para permanência da mãe nutriz durante o período de internação do seu filho, de preferência próximo ao setor de Neonatologia.

- No momento da alta, a mãe deve ser orientada sobre a importância da manutenção da amamentação e 
encaminhada ao Centro de Saúde mais próximo de sua residência, para acompanhamento precoce nos primeiros 15 dias, levando o Cartão da Criança devidamente preenchido.

- Estimular a participação de grupos comunitários de apoio ao aleitamento materno dentro das Unidades de Saúde.

Para ZAMPIRI \& OLIVEIRA (1995) o Alojamento Conjunto é primordial para o pleno desenvolvimento emocional e psíquico da criança, devido a maior aproximação do recém nascido com a sua mãe, que lhe dá carinho e segurança, além de reduzir a desnutrição infantil e a mortalidade neonatal, visto que permite e facilita o aleitamento materno.

A adoção do Alojamento Conjunto não representa de forma alguma a extinção do berçário, pois este sempre será necessário para prestar assistência aos RNs que apresentem riscos na sua adaptação à vida extrauterina, aos que tenham condições patológicas e para aqueles cujas mães não lhe possam prestar cuidados. Tampouco é um método de assistência utilizado para economizar pessoal de enfermagem, pois tem um alto conteúdo educativo e deve ser considerado prioritário.

Levando-se em conta o que foi exposto e os aspectos referentes ao Sistema de Alojamento Conjunto já implantado na Maternidade Dona Francisca Cintra Silva, este estudo teve os seguintes objetivos:

1. avaliar a aceitação do sistema pelas mães;

2. conhecer como a equipe de Enfermagem se insere e participa dessa assistência.

\section{MÉTODO}

\section{a) Local}

O trabalho foi realizado na Maternidade Dona Francisca Cintra Silva, com 24 leitos do Sistema Único de Saúde (SUS), 44 de Convênio Particular e, que adota o Alojamento Conjunto desde novembro de 1997. Tal maternidade localiza-se na cidade de São Carlos, e atende a população de inúmeras cidades da região. Conta com uma Equipe Multiprofissional constituída por: 1 Enfermeira, 54 Auxiliares de Enfermagem, 57 Médicos e 19 Funcionários sendo 09 da Administração, 03 da Copa e 07 da Limpeza.

\section{b) População}

A população constituiu-se de 196 Puérperas internadas de 09/09/98 a 08/10/98, de uma enfermeira e de 42 auxiliares de Enfermagem.

\section{c) Procedimento}

A coleta de dados foi realizada regularmente durante a disciplina Estágio Profissional: Execução de Projetos, pelas graduandas em Enfermagem da Universidade Federal de São Carlos-UFSCar, no período de setembro a outubro de 1998.

Para levantamento dos dados foram utilizados Roteiros de Entrevistas para as Puérperas e Equipe de Enfermagem (Anexos 1 e 2). Antes da sua aplicação, dialogava-se com o sujeito, explicando-se o objetivo da entrevista, se concordava em participar e, também esclarecia-se que sua identidade seria preservada.

Segundo SELTIZ et al. (1987), na entrevista e no questionário dá-se um grande peso a relatos verbais dos sujeitos para a obtenção de informações sobre as experiências a que estão expostas e para o conhecimento de seus comportamentos. A combinação da aplicação de ambos pode ser bem sucedida na obtenção de altas taxas de respostas.

\section{d) Tipo de Estudo}

Pela peculiaridade deste trabalho, optou-se por uma abordagem quanti-qualitativa visando o maior enriquecimento dos resultados apresentados.

SAUL (1988), ressalta que o propósito da avaliação qualitativa é compreender a situação, ou seja, o objeto de estudo mediante a consideração das interpretações e aspirações daqueles que nela atuam, sendo que, os métodos qualitativos de avaliação estão direcionados para enfocar os processos da prática educativa com a intenção de proporcionar a informação necessária para a formulação e reformulação racional da ação didática. Ainda, segundo esta autora, a avaliação quantitativa tem, como preocupação única, a comprovação do grau em que os objetivos previamente estabelecidos foram alcançados. A ênfase maior da avaliação está quase totalmente nos produtos ou resultados e, os modelos de avaliação estão centrados em objetivos comportamentais, análise de sistemas e aqueles cujo enfoque está na tomada de decisões.

\section{RESULTADOS DAS PUÉRPERAS}

A Tabela 1 apresenta os percentuais de amamentação apresentados pelas Puérperas, de acordo com a faixa etária. 
Tabela 1 - Puérperas segundo amamentação e faixa etária

\begin{tabular}{l|cc|cc|cc}
\hline \multicolumn{1}{c|}{ FAIXA } & \multicolumn{3}{c|}{ AMAMENTAÇÃO } & \multicolumn{2}{c}{ TOTAL } \\
ETÁRIA & \multicolumn{2}{|c|}{ SIM } & \multicolumn{2}{c}{ NÃO } & \multicolumn{2}{c}{} \\
& $\mathrm{N}^{\mathbf{5}}$ & $\%$ & $\mathrm{~N}^{\mathbf{0}}$ & $\mathscr{\%}$ & $\mathrm{N}^{\mathbf{0}}$ & $\%$ \\
\hline $14-19 \operatorname{anos}$ & 49 & 25 & 01 & 0,51 & 50 & 25,51 \\
\hline $20-29 \operatorname{anos}$ & 107 & 54,59 & 01 & 0,51 & 108 & 55,10 \\
\hline $30-39$ anos & 36 & 18,36 & 02 & 1,02 & 38 & 19,39 \\
\hline TOTAL & $\mathbf{1 9 2}$ & $\mathbf{9 7 , 9 6}$ & $\mathbf{0 4}$ & $\mathbf{2 , 0 4}$ & $\mathbf{1 9 6}$ & $\mathbf{1 0 0 , 0 0}$ \\
\hline
\end{tabular}

Das 196 Puérperas entrevistadas, 192 fizeram referência de que em algum momento já haviam amamentado. O maior índice encontrado corresponde a $54,59 \%$ das Puérperas que já amamentaram, estas situamse na faixa etária de 20 a 29 anos. A seguir apresenta-se a Tabela 2 .

Tabela 2 - Puérperas segundo conhecimento sobre alojamento conjunto e orientações recebidas na internação

\begin{tabular}{|c|c|c|c|c|c|c|}
\hline \multirow{3}{*}{$\begin{array}{c}\text { ORIENTAÇÕES } \\
\text { NA } \\
\text { INTERNAÇÖO }\end{array}$} & \multicolumn{4}{|c|}{$\begin{array}{l}\text { CONHECIMENTO SOBRE } \\
\text { ALOJAMENTO CONJUNTO }\end{array}$} & \multirow{2}{*}{\multicolumn{2}{|c|}{ TOTAL }} \\
\hline & \multicolumn{2}{|c|}{ SMI } & \multicolumn{2}{|c|}{ NÃO } & & \\
\hline & $N^{p}$ & $\%$ & $\mathrm{~N}^{\mathrm{N}}$ & $\mathscr{1}$ & $N^{p}$ & $\%$ \\
\hline $\begin{array}{l}\text { Não recebeu } \\
\text { Orientaçăo }\end{array}$ & 89 & 45,41 & 85 & 43,37 & 174 & 88,78 \\
\hline $\begin{array}{l}\text { Recebeu } \\
\text { Orientação }\end{array}$ & 13 & 6,63 & 09 & 4,59 & 22 & 11,22 \\
\hline TOTAL & 102 & 52,04 & 94 & 47,96 & 196 & 100,00 \\
\hline
\end{tabular}

Do total de 196 Puérperas entrevistadas, 102 $(52,04 \%)$ fizeram referência de que sabiam o que era Alojamento Conjunto. Destas, 45,51\%, não foram orientadas pela Instituição quanto ao Alojamento Conjunto. No entanto, 22 Puérperas receberam orientações fornecidas pelo Setor Administrativo. A seguir, apresenta-se a Tabela 3.

Tabela 3 - Puérperas segundo orientações recebidas na internação e sua avaliação da equipe de enfermagem

\begin{tabular}{|c|c|c|c|c|c|c|}
\hline \multirow{3}{*}{$\begin{array}{l}\text { AVALIAÇÃO DA } \\
\text { ENFERMA GEM }\end{array}$} & \multicolumn{4}{|c|}{$\begin{array}{l}\text { ORIENTAÇŐES NA } \\
\text { INTERNAÇÃO }\end{array}$} & \multicolumn{2}{|c|}{ TOTAL } \\
\hline & \multicolumn{2}{|c|}{ SIM } & \multicolumn{2}{|c|}{ NÃO } & & \\
\hline & $\mathrm{N}^{\mathrm{T}}$ & $\%$ & $\mathrm{~N}^{\mathrm{T}}$ & $\%$ & $N^{N}$ & $\%$ \\
\hline Bom & 16 & 8,16 & 130 & 66,33 & 146 & 74,49 \\
\hline Ótimo & 05 & 2,55 & 22 & 11,22 & 27 & 13,77 \\
\hline Regular & 00 & 0,00 & 16 & 8,16 & 16 & 8,16 \\
\hline Ruim & 01 & 0,00 & 06 & 3,07 & 07 & 3,58 \\
\hline TOTAL & 22 & 11,22 & 174 & 88,78 & 196 & 100,00 \\
\hline
\end{tabular}

A tabela mostra que 174 Puérperas $(88,78 \%)$, não receberam nenhuma Orientação na Internação, enquanto que 22 Puérperas fizeram referência de que receberam apenas orientações fornecidas pelo setor Administrativo desta instituição. Quanto à Avaliação da equipe de Enfermagem, a maior parte 146 Puérperas (74,49\%), atribuiu conceito bom à equipe de Enfermagem. A seguir, apresenta-se Tabela 4.

Tabela 4 - Puérperas segundo visita da equipe de enfermagem no início do plantão

\begin{tabular}{l|c|c}
\multicolumn{1}{c|}{ VISITA } & $\mathbf{N}^{0}$ & \% \\
\hline Sim & 39 & 19,90 \\
\hline Não & 157 & 80,10 \\
\hline TOTAL & $\mathbf{1 9 6}$ & $\mathbf{1 0 0 , 0 0}$ \\
\hline
\end{tabular}

A tabela mostra que 157 Puérperas $(80,10 \%)$, fizeram referência de que não ocorre a visita do profissional de Enfermagem no quarto no início do plantão. A seguir, apresenta-se a Tabela 5.

Tabela 5 - Puérperas segundo visita da equipe de enfermagem no final do plantão

\begin{tabular}{l|c|c}
\hline \multicolumn{1}{c|}{ VISITA } & $\mathrm{N}^{\mathrm{a}}$ & $\mathbf{\%}$ \\
\hline Sim & 41 & 20,92 \\
\hline Não & 155 & 79,08 \\
\hline TOTAL & $\mathbf{1 9 6}$ & $\mathbf{1 0 0 , 0 0}$ \\
\hline
\end{tabular}

A tabela mostra que 155 Puérperas (79,08 \%), fizeram referência de que não ocorre a visita do profissional de Enfermagem no quarto quando este sai do plantão.

\section{RESULTADOS DA EQUIPE DE ENFERMAGEM}

Em relação à Equipe de Enfermagem, pode-se observar na Tabela 6 que, ao ser abordada quanto aos pontos observados na passagem de plantão em relação à mãe, 58,1\% fizeram referência de que observavam o estado geral da paciente no pós-parto, a mama e mamilo da puérpera e, o fato de estar ou não amamentando. Quanto ao RN, 55,8\% fizeram referência de que observavam a boa pega da aréola e a sucção. Desse total, apenas $41,8 \%$ fizeram referência de que observavam o estado geral do Recém-Nascido (RN). Vale ressaltar 
novamente que a população da equipe de Enfermagem totalizou 43 sujeitos e os resultados que não correspondem a este número, correspondem a questões que não foram respondidas.

Tabela 6 - Equipe de enfermagem segundo observações na passagem de plantão

\begin{tabular}{l|cc|cc}
\hline OBSERVAÇÕES EQUIPE & \multicolumn{2}{|c|}{ MÃE } & \multicolumn{2}{c}{ RN } \\
ENFERMAGEM & $\mathbf{N}^{\mathbf{0}}$ & $\mathbf{\%}$ & $\mathbf{N}^{\mathbf{0}}$ & $\mathbf{\%}$ \\
\hline Estado geral & 25 & 58,1 & 18 & 41,8 \\
\hline Amamentação & 25 & 58,1 & 0 & 0 \\
\hline Sucção e boa pega aréola & 0 & 0 & 24 & 55,8 \\
\hline
\end{tabular}

Em relação às ações desempenhadas no início do plantão, pode-se observar pela Tabela 7 que $79 \%$ dos profissionais fizeram referência de que faziam orientações sobre os cuidados com o RN e amamentação; apenas $6,9 \%$ fizeram referência de que passavam visita ao leito e 11,6\% fizeram referência de que faziam a detecção de problemas. Nota-se também que $93 \%$ dos profissionais fizeram referência de que incentivavam a permanência do binômio no Alojamento Conjunto, através de aulas, incentivo ao Aleitamento Materno e o maior contato da mãe com o bebê.

Tabela 7 - Equipe de enfermagem segundo atividades desempenhadas no início do plantão e incentivo ao alojamento conjunto

\begin{tabular}{l|c|c}
\hline \multicolumn{1}{c|}{$\begin{array}{c}\text { ATIVIDADES EQUIPE } \\
\text { ENFERMAGEM }\end{array}$} & $\mathrm{N}^{\mathrm{a}}$ & $\mathbf{\%}$ \\
\hline Orientações & 34 & 79,0 \\
\hline Visita & 03 & 6,9 \\
\hline Detecção de Problemas & 05 & 11,6 \\
\hline Incentivo Alojamento Conjunto & 40 & 93,0 \\
\hline
\end{tabular}

A seguir pode-se observar nas Tabelas 8 e 9 , que a elaboração de programas educativos se faz presente segundo 48,8\% dos profissionais através das aulas; $32,5 \%$ fizeram referência de que era pela orientação na amamentação. No entanto, 39 profissionais fizeram referência de que não havia orientações para os pais e familiares e 02 fizeram referência de que não havia ações educativas. Segundo $60,4 \%$ dos profissionais, a elaboração do plano de assistência é feita individualmente e apenas $32,5 \%$ dos profissionais fizeram referência de que o elaboravam em grupo.
Tabela 8 - Equipe de enfermagem segundo elaboração programas educativos

\begin{tabular}{l|c|c}
\hline $\begin{array}{l}\text { ELABORAÇ̃̃o PROGRAMAS } \\
\text { EDUCATIVOS }\end{array}$ & $\mathrm{N}^{\mathbf{0}}$ & $\mathbf{\%}$ \\
\hline Aula & 21 & 48,8 \\
\hline Orientação Amamentação & 14 & 32,5 \\
\hline Ausência Orientações Pais/Familiares & 39 & 90,6 \\
\hline AusênciaAções Educativas & 2 & 4,6 \\
\hline
\end{tabular}

Tabela 9 - Equipe de enfermagem segundo elaboração plano assistência

\begin{tabular}{l|c|c}
\hline $\begin{array}{l}\text { ELAB ORAÇÃO PLANO } \\
\text { AS SISTÊNCIA }\end{array}$ & $\mathbf{N}^{\mathrm{0}}$ & $\mathbf{\%}$ \\
\hline Individual & 26 & 60,4 \\
\hline Grupo & 14 & 32,5 \\
\hline
\end{tabular}

Ao avaliar o Sistema de Alojamento Conjunto, pode-se observar através da Tabela 10 que os profissionais apontaram que as vantagens são: o incentivo ao Aleitamento Materno $(39,6 \%)$ e o estabelecimento do vínculo afetivo entre mãe e bebê $(58,1 \%)$. Em contra partida, alguns profissionais apontaram que as desvantagens são: o baixo número de funcionários $(41,8 \%)$ e planta física inadequada, com quartos pequenos $(25,5 \%)$. Ainda $16,2 \%$ dos profissionais fizeram referência de que muitas vezes a mãe não quer participar do Alojamento Conjunto.

Tabela 10 - Equipe de enfermagem segundo vantagens e desvantagens do alojamento conjunto

\begin{tabular}{|c|c|c|c|c|c|c|c|c|c|c|}
\hline & \multicolumn{2}{|c|}{$\begin{array}{l}\text { INCENTIVO } \\
\text { ALEIT.MAT }\end{array}$} & \multicolumn{2}{|c|}{$\begin{array}{l}\text { víNCULO } \\
\text { AFETIVO }\end{array}$} & \multicolumn{2}{|c|}{$\begin{array}{l}\text { BALXON } \\
\text { FUNC. }\end{array}$} & \multicolumn{2}{|c|}{$\begin{array}{l}\text { PLANTA } \\
\text { INADEQ. }\end{array}$} & \multicolumn{2}{|c|}{$\begin{array}{l}\text { RECUSA } \\
\text { MÄE }\end{array}$} \\
\hline & $N^{N}$ & $\%$ & & $\%$ & $N^{p}$ & $\%$ & $N^{P}$ & $\%$ & $N^{p}$ & $\%$ \\
\hline Vantagens & 17 & 39,6 & 25 & $\$ 8,1$ & & & & & & \\
\hline Degrantzens & & & & & 18 & 41,8 & 11 & 25,5 & 07 & 16,2 \\
\hline
\end{tabular}

Em relação às críticas feitas ao Sistema, pode-se observar na Tabela 11 que 15 profissionais fizeram referência de que os Médicos indicam pomadas para as mamas e chucas para o bebê; 11 fizeram referência do despreparo dos profissionais; 10 fizeram referência de que os Pediatras não contribuem para o Aleitamento Materno e, 04 criticaram o fato do RN tomar banho apenas uma vez ao dia. 
Tabela 11 - Equipe de enfermagem segundo críticas do alojamento conjunto

\begin{tabular}{l|c|c}
\hline \multicolumn{1}{c|}{ CRITICAS } & $\mathrm{N}^{\mathbf{0}}$ & $\mathbf{\%}$ \\
\hline Pomadas e Chucas & 15 & 34,9 \\
\hline Despreparo Profissionais & 11 & 25,6 \\
\hline $\begin{array}{l}\text { AusênciaContribuição } \\
\text { Pediatras }\end{array}$ & 10 & 23,25 \\
\hline Banho RH & 4 & 9,3 \\
\hline
\end{tabular}

No que diz respeito às sugestões pode-se observar na Tabela 12, o que a equipe de Enfermagem poderia oferecer para a melhoria deste Sistema: $30,2 \%$ do profissionais sugeriram a necessidade de aumentar o número de profissionais da equipe de Enfermagem; $27,9 \%$ citaram o início das orientações sobre Alojamento Conjunto durante o acompanhamento pré-natal; 25,5\% sugeriram a melhoria da infra-estrutura e, 16,2\% citaram a instalação do banho do RN no Alojamento Conjunto.

Tabela 12 - Equipe de enfermagem e sugestões para melhorar o sistema

\begin{tabular}{l|c|c}
\hline \multicolumn{1}{c|}{ SUGESTÕES } & $\mathbf{N}^{\mathbf{0}}$ & $\mathbf{\%}$ \\
\hline Aumentar $\mathrm{N}^{\circ}$ Profissionais & 13 & 30,2 \\
\hline Início Orientações Pré-Natal & 12 & 27,9 \\
\hline Melhoria Infra-estrutura & 11 & 25,5 \\
\hline Instalação Banho & 07 & 16,2 \\
\hline Autonomia Aguatnidex & 08 & 18,6 \\
\hline
\end{tabular}

Dentre as sugestões oferecidas, vale destacar que $18,6 \%$ profissionais fizeram referência de que há necessidade de autonomia para a administração de água com nidex durante a madrugada, quando o bebê chorar. Desta forma, o bebê se acalmará e conseqüentemente a mãe.

\section{CONCLUSÃO}

Baseados nas respostas dadas pelas Puérperas em relação ao Sistema de Alojamento Conjunto, pode-se observar que a maior parte desta população já havia amamentado e 52,04\% referiu saber o que era Alojamento Conjunto. No entanto, a maior percentagem $(88,78 \%)$ não foi orientada em relação a este sistema. A minoria $(11,22 \%)$ que recebeu orientações em relação às normas e rotinas da instituição, recebeu-as do Setor Administrativo.

Quanto à equipe de Enfermagem, pode-se dizer que $58,1 \%$ se preocupa com a amamentação e, 55,8\% com a sucção e a boa pega da aréola. Um total de 79\% proporciona também orientações sobre os cuidados com o RN e 93\% incentiva a permanência do binômio no Alojamento Conjunto.

Ao ser questionada em relação às vantagens do Alojamento Conjunto, o incentivo ao Aleitamento Materno (39,6\%) e o estabelecimento de vínculo afetivo entre mãe e bebê $(58,1 \%)$ foram apontados e, em relação às desvantagens foi o baixo número de funcionários $(41,8)$

Portanto, baseado no que foi apresentado, podese dizer que o Sistema de Alojamento Conjunto da instituição estudada, não está implantado efetivamente, encontrando-se ainda com muitas deficiências em sua assistência e dinâmica do trabalho.

Percebe-se que não existe integração entre o Sistema Administrativo e a equipe de Enfermagem, cada um fazendo aquilo que considera adequado. Mesmo entre os membros da equipe de Enfermagem, observa-se que nem todos estão esclarecidos das suas funções dentro do Alojamento Conjunto.

Desta forma, considera-se fundamental que a instituição capacite seus recursos humanos com técnicas educativas e conhecimentos mais abrangentes para que possam abordar a interação mãe-filho e as suas relações familiares de maneira adequada, garantindo assim efetivamente sua implantação.

\section{EVALUATION OF THE ROOMING-IN AT THE "D. FRANCISCA CINTRA SILVA" MATERNITY - SANTA CASA HOSPITAL AT THE MUNICIPALITY OF SÃO CARLOS-SP}

The rooming-in was implemented at a maternity at the municipality of São Carlos in 1997. This study analyzes the acceptance of the system by mothers and how nursing participates in this work. Results showed that mothers are satisfied. However, the nursing team does not agree with this evaluation, confirming the need of increasing the number of workers as well as qualifying them. 


\section{EVALUACIÓN DEL SISTEMA DE ALOJAMIENTO CONJUNTO DE LA MATERNIDAD D. FRANCISCA CINTRA SILVA DE LA SANTA CASA DE SÃO CARLOS-SP}

El alojamiento conjunto fue implantado en una Maternidad en el municipio de São Carlos en 1997. Este estudio analiza la aceptación del sistema por parte de las madres y como enfermería participa en este trabajo. Los resultados han evidenciado que las madres están satisfeitas. Sin embargo, enfermería no concuerda, sugiriendo la necesidad de aumentar y mejorar la calidad del cuadro de funcionarios.

TÉRMINOS CLAVES: alojamiento conjunto, enfermería neonatal

\section{ANEXO 1 - PUÉRPERA}

Idade:

$\mathrm{N}^{\mathrm{o}}$ de partos

Você alguma vez já amamentou? ( ) sim （ ) não

Você sabe o que é Alojamento Conjunto?

\section{ANEXO 2 - EQUIPE DE ENFERMAGEM}

Categoria:
( ) Enfermeira
( ) Auxiliar de Enfermagem

\section{Passagem de Plantão:}

Pontos observados em relação a:

Mãe:

$\mathrm{RN}$ :

Elaboração do plano de Assistência:
( ) individual
( ) grupal

Ocorre incentivo ao binômio para a permanência em Alojamento conjunto? De que forma?

\section{REFERÊNCIAS BIBLIOGRÁFICAS}

01. BASSETO, M.C.; BROCK, R.; WAJNSZTEJN, R. Neonatologia - Um convite à atuação fonoaudiológica. São Paulo: Editora Lovise, 1998. p. 59-61.

02. BRASIL. Ministério da Previdência e Assistência Social. Alojamento conjunto. Normas básicas.

Rev. Paul. Pediatria, v. 3, n. 9, p. 50-1, 1991.

03. BRENELLI, M.A. Alojamento conjunto. In: NEME, B. Obstetrícia básica. São Paulo: Sarvier, 1995.
Recebeu orientação a respeito desta sistema? Se sim, quem a orientou?

Cada vez que troca o plantão da equipe de Enfermagem, você recebe a visita do:

Profissional que está entrando ( ) sim ( ) não

Profissional que está saindo ( ) sim ( ) não

Que conceito você atribuiria à equipe de Enfermagem?

Ocorre a elaboração de programas educativos? Quais são as prioridades?

Há orientações para pais e familiares? ( ) sim （ ) não

Se sim, quais?

Por favor, dê a sua opinião sobre o Alojamento Conjunto em relação a:

Vantagens

Desvantagens

Críticas

Sugestões:

04. CAMPOS, J.C. et al. Manual de cuidados primários. Rio de Janeiro: Sociedade Brasileira de Pediatria, 1994.

05. CARVALHO, A.B.R.; THOMSON, Z. Alojamento conjunto: análise da opinião de puérperas. Jornal de Pediatria, v. 9, n. 3/4, p. 124-8, 1987.

06. CIAMPO, L.A. et al. Influências dos diferentes tipos de Alojamento conjunto sobre recém-nascidos na prática do aleitamento materno. Jornal de Pediatria, v. 70, n. 1, p. 10-5, 1994. 
07. CZAR, C.M.; RIBEIRO,C.D. O sistema de alojamento conjunto para $\mathrm{RN}$ e mãe. Rev.Bras.Enfermagem, v. 34, n. 1, p. 48-54, janmar.1981.

08. FONTES, J.A.S. Perinatologia social. São Paulo: Fundo Editorial BYK, 1984.

09.FREDDI, W.E.S.; SCHUBERT, M.Z.B. Considerações gerais sobre "rooming in" (alojamento conjunto). Rev. Bras. Enfermagem, v. 30, n. 3, p. 136-44, 1987.

10. PRATA, N.S. Avaliando a adesão às orientações para a higiene do recém-nascido oferecidas no sistema alojamento conjunto: opinião materna. Rev. Enfermagem UERJ, v. 5, n. 1, p. 299-305, maio 1997.

11. SAUL, A. M. Avaliação emancipatória. São Paulo: EPU, 1988.
12. SELTIZ, C. et al. Métodos de pesquisa nas relações sociais. São Paulo: EPU, 1987.

13. SILVA, C. et al. Alojamiento conjunto madre-hijo e inicio de amamantamiento, en un hospital de tercer nivel de atención. Salud Publica Mex., v. 37, n. 5, p. 424-9, sept.-oct. 1995.

14. UNICEF/OMS/OPAS. Dez passos para o sucesso do aleitamento materno. Brasília: Ministério da Saúde -Grupo de Defesa da Saúde da Criança, 1993.

15. ZAMPIRI, M.F.M.; OLIVEIRA, A.R. Análise do alojamento conjunto na Maternidade Darcy Vargas: opinião e aceitação das puérperas e profissionais de saúde. Rev. Ciênc. Saúde, v. 14, n. 1/2, p. 7-22, jan.-dez. 1995. 